\title{
COMUNICAÇÃO DIALÓGICA ESTRATÉGI- CA PARA A PREVENÇÃO \\ E GESTÃO DE CRISE NO CONTEXTO DAS ORGANIZAÇÕES
}

ROSÂNGELA FLORCZAK OLIVEIRA ESCOLA SUPERIOR DE PROPAGANDA E MARKETING PORTO ALEGRE, RIO GRANDE DO SUL, BRASIL ROFLORCZAK@GMAIL.COM 


\section{COMUNICAÇÃo DIALÓGICA ESTRATÉGICA PARA A PREVENÇÃo E GESTÃO DE CRISE NO CONTEXTO DAS ORGANIZAÇÕES}

Resumo: Na sociedade marcada pela midiatização (HJARVARD, 2014, 2015) do cotidiano, a comunicação, compreendida como mecanismo de negociação entre lógicas e interesses distintos (WOLTON, 2006 e 2010), assume lugar central no contexto das organizações. Estudo exploratório teórico investiga o lugar da comunicação dialógica estratégica (PÉREZ, 2012; OLIVEIRA, 2016) na prevenção e gestão de crise.

Palavras-chave: Comunicação Organizacional; Comunicação estratégica; Cultura do Cuidado; Prevenção de Crise; Gestão de Crise.

\section{COMUNICACIÓN DIALÓGICA ESTRATÉGICA PARA LA PREVENCIÓN Y GESTIÓN DE CRISIS EN EL CONTEXTO DE LAS ORGANIZACIONES}

Resumen: En la sociedad marcada por la mediatización (HJARVARD, 2014, 2015) de la vida cotidiana, la comunicación, entendida como un mecanismo de negociación entre diferentes lógicas e intereses (WOLTON, 2006 y 2010), ocupa un lugar central en el contexto de las organizaciones. El estudio exploratorio teórico investiga el lugar de la comunicación dialógica estratégica (PÉREZ, 2012; OLIVEIRA, 2016) en la prevención y gestión de crisis.

Palabras Clave: Comunicación Organizacional; Comunicación estratégica; Cultura del cuidado; Prevención de crisis; Manejo de crisis.

\section{STRATEGIC DIALOGICAL COMMUNICATION FOR PREVENTION} AND CRISIS MANAGEMENT IN THE CONTEXT OF ORGANIZATIONS Abstract: In a society marked by mediatization (HJARVARD, 2014, 2015) of everyday life, the communication, understood as a mechanism of negotiation between different logics and interests (WOLTON, 2006 and 2010), takes center stage in the context of organizations. Theoretical exploratory study investigates the place of strategic dialogical communication (PÉREZ, 2012; OLIVEIRA, 2016) in crisis prevention and management.

Keywords: Organizational Communication; Strategic communication; Care Culture; Crisis prevention; Crisis management.

\section{CONTEXTUALIZAÇÃO DO ESTUDO}

Em momentos de crise, Forni (2013, p. 289) defende que a comunicação é um diferencial. "Sem uma comunicação efetiva, transparente, tempestiva, fica muito mais difícil controlar a crise". A afirmação do autor, aparentemente simples, nos provoca a compreender diferentes dimensões de cenários carregados de complexidade: o mundo marcado por incertezas, as organi- 
zações imersas em uma nova lógica relacional, as crises que marcam o cotidiano, assim como a compreensão do conceito e do lugar da comunicação no contexto organizacional.

Considerando que os riscos, eventos críticos e crises passaram a ser o novo comum no cotidiano social e organizacional, mais do que entender o sentido de cada termo que envolve o processo de gestão de crise, a pesquisa científica e as práticas do mercado podem, recursivamente, se desenvolver para que se amplie o olhar para fenômenos complexos que cercam o tema da gestão de crise. Para propor alguns avanços, partimos da questão central: como a comunicação, no contexto das organizações, pode contribuir para a prevenção e gestão de crise?

Para responder a inquietação fundante desse esforço de pesquisa, desenvolvemos uma investigação exploratória teórica interdisciplinar que tem como objetivo central apresentar as possibilidades da comunicação no contexto das organizações para que seja possível aprimorar a prevenção e a gestão de crise nos cenários complexos contemporâneos. Na pesquisa usamos as lentes do Paradigma da Complexidade (MORIN, 2015) como conjunto de pressupostos para produção provisória do conhecimento.

Interdisciplinarmente investigamos o tema proposto de forma dialógica (MORIN, 2015). Como procedimento metodológico, exploraremos as contribuições teóricas de cada dimensão estudada com aportes teóricos das Ciências Sociais, das Ciências da Comunicação; do campo da Comunicação Organizacional, da perspectiva da Comunicação na ambiência digital, das Ciências Administrativas, entre outros. Posteriormente, entrecruzamos, dialogicamente, as contribuições de diferentes autores de forma a tecer junto o conjunto de possibilidades que poderá levar a aprimoramento do olhar sobre o lugar da comunicação no contexto das organizações na prevenção e gestão de crise.

\section{COMPLEXIDADE DO MUNDO E DAS ORGANIZAÇÕES}

"Viver é uma aventura que implica incertezas sempre renovadas, eventualmente com crises ou catástrofes pessoais e/ou coletivas" (MORIN, 2015, p. 25). E viver é, justamente, enfrentar incessantemente as incertezas. Pois o mundo em sua configuração contemporânea é apresentado por Giddens (2007) como um tempo de profundas transformações que afetam os diferentes aspectos do que fazemos e da forma como convivemos socialmente. “Há uma revolução global em curso no modo como pensamos sobre nós 
mesmos e no modo como formamos laços e ligações com outros" (GIDDENS, 2007, p.61).

Hologramaticamente (MORIN, 2015), as organizações estão situadas nesse ambiente complexo em que a imprevisibilidade é o elemento que permeia todos os contextos macro e micro organizacional (SILVA e REBELO, 2003). Se partirmos da proposição de Morin (2015) de que entramos em uma grande época de incertezas sobre nossos futuros, torna-se compreensível que as organizações - partes do todo social - enfrentem a ordem e a desordem que caminham juntas em um mundo sem fronteiras (SILVA e REBELO, 2003, pp 778 e 779).

Esse novo conceito desafia, para Silva e Rabelo (2003), os fundamentos do paradigma cartesiano-newtoniano que, conforme os autores, estão ancorados em relações ordenadas de causa e efeito entre eventos, na dualidade e separação entre sujeito e objeto e na busca da máxima objetividade. Questiona, também, a observação pretensamente neutra e imparcial que procura uma maior previsibilidade, regularidade, quantificação e controle.

Entre as inúmeras consequências dessas incertezas no mundo das organizações, está a perspectiva do novo evocada por Wheatley (2006). Ela defende que estamos próximos do mundo das relações, que é rico e complexo e com ele desistiremos da previsibilidade e daremos boas-vindas às potencialidades, tornando-as como base de todas as definições. A partir desta perspectiva, abandona-se a ideia de previsão e reprodução exatas visto que o importante é a relação que se cria entre dois e/ou mais elementos. "Os sistemas influenciam os indivíduos, e os indivíduos fazem com que os sistemas venham a existir. É a relação que evoca a realidade presente" (WHEATLEY, 2006, p.57).

Entre os diferentes aspectos que marcam o sistema dos relacionamentos que tornam a realidade presente, compreender um deles torna-se fundamental no contexto de nossa problematização teórica: o fenômeno da midiatização (HJARVARD, 2014). Compreendida como um processo contínuo estudado em interface pela Sociologia e pela Comunicação, entre outros campos disciplinares, a midiatização, conforme Hjarvard (2015a) enfoca o papel da mídia nas transformação das relações sociais e culturais. Diante das mídias digitais, o autor defende que a midiatização deveria ser vista como um processo de modernização comparável à globalização, à urbanização e à individualização. 
No contexto das mídias digitais surgidas com a internet, para que a teoria da midiatização dê conta de explicar o impacto dessas novas mídias no comportamento individual, organizacional e social, será preciso considerar as características chave e funções sociais da mídia em vez de focar em tipos particulares de mídia (HJARVARD, 2015). Nos interessa compreender que em meio às profundas transformações vividas pela sociedade e pelas organizações, está a importância intensa e transformadora da mídia na cultura e na sociedade. Como defende Hjarvard (2015) cultura e sociedade tornam-se cada vez mais dependentes das mídias e seus modus operandi, ou lógica da mídia. A lógica da mídia digital tem impactado o mundo das relações no ambiente organizacional apontado por Weatlhey (2006).

Castells (2009) exemplifica esse impacto ao afirmar que o poder na atualidade está relacionado à conexão e/ou desligamento das redes. Para o autor, o poder na sociedade em rede é o poder da comunicação (CASTELLS, 2009, p. 85). E, por isso, a disputa pelo poder relaciona-se à batalha para a construção de significado na mente das pessoas. Os indivíduos criam significado interagindo com seu ambiente e se conectando com as redes sociais, que são: “[...] espaços de autonomia, muito além do controle de governos e empresas, que, ao longo da história, haviam monopolizado os canais de comunicação como alicerces de seu poder" (CASTELLS, 2013, p. 10).

Hjarvard (2015) afirma que as mídias estão ao mesmo tempo fora da sociedade, e dentro como parte das práticas do mundo vivido na família, no local de trabalho, entre outros. "Como resultado, a interação social dentro das instituições, entre as instituições e na sociedade em geral - cada vez mais envolve a mídia" (HJARVARD, 2015, p. 53). Em uma visão da potencialidade da ambiência digital, Santaella (2013) diz que, além de favorecer a circulação, as mídias sociais abrem espaços para a criação de ambiente de convivência instantânea entre as pessoas. Ampliamos para o universo das organizações que, neste ambiente se posicionam como um sujeito em interlocução. "Instauram assim, uma cultura integrativa, assimilativa, cultura da convivência que evolui de acordo com as exigências impostas pelos participantes [...]. A internet tornou-se assim um hiperespaço plural [...] em um sistema de trocas e reciprocidade" (SANTAELLA, 2013, p. 45).

Compreendemos, portanto, que a sociedade e a organização vivem um processo de profunda transformação marcado por incertezas, pela falência do paradigma newtoniano-cartesiano e pela emergência de novas lógicas relacionais influenciadas por fenômenos como a midiatização do cotidiano por 
meio da mídias digitais. É nesse contexto que são percebidas e gerenciadas as crises que afetam a sociedade, mas aqui especificamente presentes em nosso foco de investigação, que são vividas no contexto das organizações.

\title{
3 PREVENÇÃo E GESTÃo DE CRISE - UMA VISÃO PROCESSUAL
}

Em 1986, Beck (2008) apresentou ao mundo a Sociedade de Risco, o que ele considerou como uma condição estrutural inegável da industrialização avançada. Criador da Teoria da Sociedade de Risco Mundial, o autor afirma que: "A sociedade moderna se tornou uma sociedade de risco à medida que se ocupa, cada vez mais, em debater, prevenir e administrar os riscos que ela mesma produziu" (BECK, 2008, p.1). Ele esclarece a diferença entre risco e catástrofe.

\begin{abstract}
Risco não significa catástrofe. Risco significa a antecipação da catástrofe. Os riscos existem em um estado permanente de virtualidade, e transformam-se em "atuais" somente até o ponto em que são antecipados. Riscos não são "reais", eles estão se tornando "reais" (Joost van Loon). Neste momento em que os riscos se tornam reais - por exemplo, na forma de um ataque terrorista - eles deixam de ser riscos e tornam-se catástrofes. Os riscos já estão em outras partes: na antecipação de novos ataques, nas mudanças climáticas ou em uma crise financeira potencial. Riscos são sempre eventos ameaçadores (BECK, 2008, pp.1 e 2).
\end{abstract}

Para Almeida (2011), o conceito risco está ligado a três fatores: (1) Incertezas na realização do acontecimento e nas respectivas condições e características de realização, (2) Intensidade de atuação e (3) Consequências, efeitos ou danos provocados pelo impacto de um acontecimento. Para o autor, é necessário um processo gerenciável sobre o risco, uma vez que a sensação ou percepção fluída do perigo é insuficiente para a tomada de decisões racionalizadas, envolvendo diferentes alternativas que possam ser avaliadas de um modo consistente e comparável.

Aceitando aqui que vivemos na Sociedade do Risco e admitindo que os riscos não gerenciados podem se transformar em crises que afetam pessoas e organizações, em nosso entendimento, a concepção e gestão do risco é uma das dimensões do que denominamos como processo e/ou sistema de prevenção e gestão de crise. Pelo cenário contemporâneo de incertezas, tona-se necessário transcender a tradicional visão centrada na contenção circunstancial das crises ampliando nossa visão para um sistema que inclua 
todas as dimensões do fenômeno.

Conforme Shinyashiki (2006), na gestão de crises, são consideradas desde as ações de prevenção até os cuidados pós-evento surpreendente. Definindo crise como processos de degeneração e ameaças à organização que se manifestam em eventos súbitos, o autor afirma que esses eventos podem colocar em risco a sobrevivência ou provocar perdas humanas, financeiras e de reputação. Denominados de maneiras diversas como incidentes críticos (COTTA, 2009), eventos surpreendentes (SHINYASHIKI, 2006), ou de forma mais geral, termos simples como problema, acontecimento negativo, entre outros, aqui denominaremos o evento com potencial desencadeador da crise como evento crítico. Temos, portanto, duas dimensões já definidas em nossa visão processual de gestão de crises: o risco e o evento crítico.

Como proposição um modelo de ações para gestão de crises, Shinyashiki, Fischer e Shinyashiki (2007) categorizam as contribuições de autores internacionais que pesquisam o tema e listam a necessidade de um conjunto integrado de ações. Fazem parte: a prevenção das crises; procedimentos de contingência; atenção aos stakeholders; comprometimento da direção; comunicação; liderança; manutenção dos valores; criatividade; rapidez nas ações e cuidados pós-crise. A partir das etapas propostas propusemos aqui o que denominamos como Sistema de Prevenção e Gestão de Crise, a partir de uma visão processual (Figura 1).

Figura 1: Sistema de Prevenção e Gestão de Crise

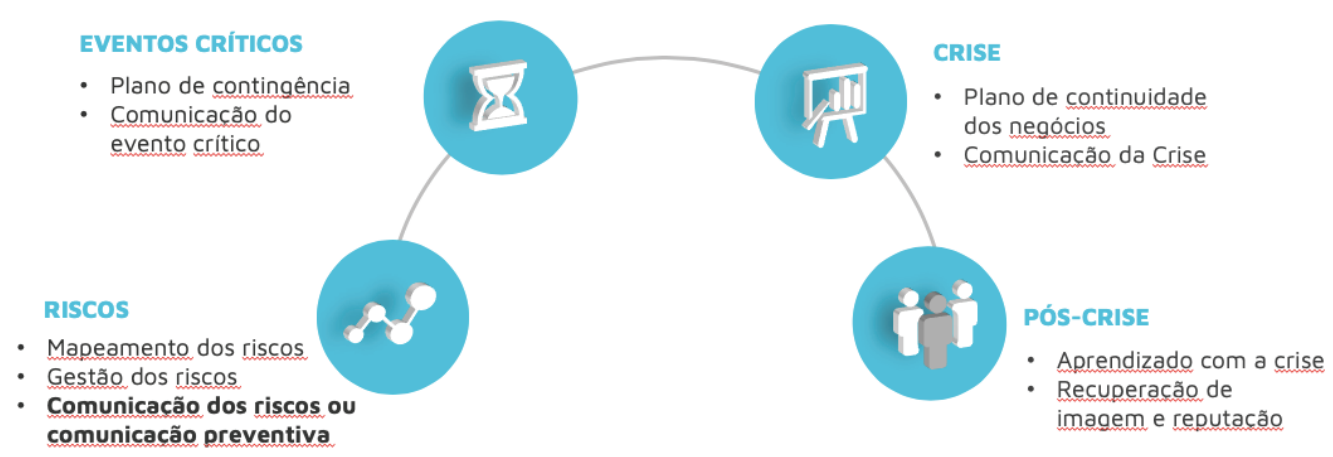

Fonte: A autora (2019)

O sistema proposta traz como elemento central a presença da comunicação nas diferentes etapas da prevenção e gestão das crises. Em cada 
etapa, a comunicação assume diferentes responsabilidades. Para Steelman e MCCaffrey (2013), enquanto a comunicação de risco o foco é a prevenção de danos, na comunicação de crises o foco é a comunicação durante um evento. A comunicação assume, portanto, um lugar central no processo de prevenção e gestão. Precisamos, então, considerar sobre qual a comunicação que estamos falando?

\title{
4 COMUNICAÇÃO NO CONTEXTO DAS ORGANIZAÇÕES
}

Termo polissêmico que integra o conjunto de saberes de diversas ciências, Comunicação para Martino (2001) apresenta um sentido particular em cada uma delas, mas todos derivam do seu sentido original: "pôr em relação" (MARTINO, 2001, p.24).

\begin{abstract}
[...]. Afirmar o homem como um ser simbólico é afirmar um ser que somente se deixa apreender nas relações que estabelece com seus semelhantes. Em outras palavras, o ser humano é um ser de comunicação consigo (subjetividade) e com o mundo, ambos entendidos como produtos da comunicação com outrem, pois assim como a subjetividade não é um dado natural, as coisas não se apresentam ao ser humano de forma direta, mas são construídas graças a mediação do desejo, conhecimento e reconhecimento de outrem (MARTINO, 2001, p. 23).
\end{abstract}

A comunicação é apresentada como processo social permanente, que integra múltiplos modos de comportamento: a fala, o gesto, o olhar, o espaço interindividual. Mattelart e Mattellart (1997, p. 69) afirmam: "A análise do contexto se sobrepõe à do conteúdo". Para o contexto que pesquisamos, destacamos aqui a inclusão de uma visão complexa da comunicação que começou a ser construída a partir do paradigma dialógico (FRANÇA, 2001). Surge, então, a perspectiva da bilateralidade do processo comunicacional, que se caracteriza pela igualdade de condições entre os interlocutores envolvidos, enfatizando, não a diferença entre os polos (emissor e receptor), mas a natureza da relação estabelecida entre ambos. Os processos comunicativos põem em cena, para França (2006), indivíduos investidos de um novo papel: sujeitos da comunicação, sujeitos em comunicação.

Na complexidade do tempo vivido, a comunicação precisa ser entendida para além da mera transmissão de informações e ser colocada no tenso espaço da confiança, do vínculo e das relações. "Informar, expressar-se e transmitir não são mais suficientes para criar uma comunicação” (WOLTON, 
2006, p.31). Para que a comunicação aconteça, embora se saiba que no horizonte das relações é permanente a presença do risco da incomunicação, parte-se da questão central que é o outro. O outro que aqui assume o lugar de interlocutor. E como afirma Wolton (2010), é aí que tudo se complica.

Os estudos da comunicação no contexto das organizações se inserem na perspectiva multidisciplinar que busca compreender o espaço das interações na vida e nas relações estabelecidas entre os sujeitos que configuram as organizações. Como afirma Pinto (2008), quando nos afastamos dos modelos sistêmicos convencionais e nos aproximamos das perspectivas relacionais, assumimos que os processos comunicativos se tornam dependentes de interpretações muitas vezes conflitantes, pois a organização passa a ser vista como uma "rede dinâmica de sentidos em constante produção" (PINTO, 2008, p. 45).

O foco dessa perspectiva está na interação que é tida como uma construção negociada, ou seja, a relação se (re) define permanentemente com a interação dos interlocutores. "[...] O papel da comunicação no contexto organizacional é, então, de mediadora e organizadora desses processos de interação" (LIMA e BASTOS, 2012, p.40).

Compreender a comunicação no contexto das organizações a partir do paradigma dialógico relacional da comunicação, é possível considerar a comunicação como o resultado da construção de sentido que se dá na ação e na interação (trocas simbólicas) que recheiam as relações entre sujeitos organizacionais (OLIVEIRA, 2016).

Para Oliveira (2016), tendo a comunicação como resultado do processo de interação entre sujeitos no contexto das organizações é possível compreender duas diferentes e complementares dimensões com as seguintes denominações: comunicação estabelecida como resultado de processos de interação dialógica espontânea - espaço no qual situam-se as construções de sentido frutos da interação e ação não planejadas entre os sujeitos organizacionais em qualquer espaço; e a comunicação estabelecida como resultado de processos de interação dialógica estrategicamente gerida pela organização - espaço institucionalizado a partir do qual as organizações investem na (re) construção de sentidos que favoreçam a criação, manutenção e/ou mudança de reputação ${ }^{1}$ junto aos demais sujeitos organizacionais

1 Fruto do processo de significação e construção de sentido sobre a organização, a reputação é a consolidação das diversas imagens construídas ao longo do tempo, ou seja, uma representação coletiva cristalizada com base nos resultados de repetidas interações 
em interlocução.

Conforme Oliveira (2016), o termo dialógica, neste contexto, se refere justamente ao processo interativo de busca de construção de sentido entre os sujeitos organizacionais. A autora compreende que só podemos denominar comunicação quando há algo além da troca informacional, quando há interação dialógica.

Essa compreensão de comunicação encontra suporte teórico na perspectiva teórica da Comunicação Estratégica (PÉREZ, 2012). Complexa, fluída e significativa, é a partir destas características que Pérez (2012) visualiza a presença dos pressupostos dos paradigmas emergentes na produção teórica sobre a comunicação estratégica. Para Massoni (2008), a perspectiva da comunicação estratégica é hoje um espaço de reflexão em torno do grande deslocamento que se produziu no pensamento e na ação comunicacional nas últimas décadas.

Para um mundo linear como concebido no paradigma clássico da produção do conhecimento, havia, segundo Massoni (2008), continuidade, princípio, meio e fim, além de uma pretensa clareza de quem era o emissor e qual o lugar de cada integrante do processo comunicacional. Hoje, no mundo fluído não há um narrador central, nem emissores tão claramente definidos como fontes, nem conteúdos tão unívocos, mas transformações permanentes nas quais todos são atores múltiplos em uma construção conjunta, aberta e permanente de sentidos.

Pérez (2012) defende que a comunicação estratégica, fruto do pensamento complexo, implica não só em falar e divulgar, mas também, escutar e dialogar (grifo nosso), buscar mais articulação que persuasão, mais conectividade que difusão, compartilhar e harmonizar percepções e valores mais que impor valores. Além disso, o autor sugere que a comunicação seja lugar de encontro e geração de significado e de sentido compartilhado.

Consideramos que a comunicação estratégica é uma das abordagens possíveis baseadas no paradigma dialógico relacional, que situa os sujeitos organizacionais em um mundo complexo, não linear, marcado pela transformação, pelas incertezas e pela complexidade, no qual os emissores e receptores não são definidos por lugar hierárquico e geram interações permanentes, intercalando o lugar de escuta e diálogo, espaço no qual constroem o

e experiências acumuladas entre a organização e seus interlocutores (ALMEIDA, PAULA e BASTOS, 2012). 
sentido a partir das trocas comunicacionais.

No diálogo, o horizonte de questionamento se dá a partir de uma abertura ao outro que inclui pôr-se na sua posição frente ao horizonte, sem que para isso se precise chegar a um entendimento com o dialogante. Não se trata de conceber o diálogo como estabelecimentos de entendimentos em nível de consensos, mas de se chegar a compreensões sem que para isso se precise de convencimentos. Trata-se de uma concepção de diálogo que resguarda as diferenças. O que une os dialogantes não é o entendimento a que possam chegar, mas o horizonte comum - a tradição que compartilham (CARBONARA, 2013, p. 105).

A partir de Oliveira (2016), compreendemos que Diálogo é um processo que se estabelece a partir de interações recíprocas, com abertura para o outro, portanto, baseado na alteridade. Dá-se entre sujeitos interlocutores, de forma mediada, ou não, exigindo engajamento efetivo na interpretação e construção de realidades. Tem potencial de transformação, a partir do estabelecimento de vínculos de cooperação. De rara ocorrência, implica superar a solidão dos monólogos para construir, conjuntamente, novas interpretações sobre o mundo de forma dialógica, ou seja, permanente, imprevisível e caótica.

É, pois, a perspectiva da comunicação dialógica estratégica que podemos compreender os diferentes sentido da comunicação na prevenção e na gestão de crise.

\section{CONSIDERAÇÕES FINAIS}

Buscando apresentar as possibilidades da comunicação no contexto das organizações para que seja possível aprimorar a prevenção e a gestão de crise nos cenários complexos contemporâneos, percorremos um itinerário de exploração teórica que tornou evidente a complexidade enfrentada pela sociedade e pelas organizações. No espaço marcado pelas incertezas e pela midiatização do cotidiano, encontra-se a Sociedade do Risco Mundial (BECK, 2008).

A frequente ocorrência de eventos críticos que levam a situações de crises e podem colocar em risco a sobrevivência da organização ou provocar perdas humanas, financeiras e de reputação exige que ampliemos a visão circunstancial das crises, assumindo a visão processual que considera todo o sistema de prevenção e gestão da crises. Elemento constante no processo 
é a comunicação, presente desde a comunicação do risco até os cuidados pós-crise.

Para que a comunicação seja efetiva, considerando que é o processo que apoia a construção de sentido entre sujeitos com lógicas e interesses distintos, também a comunicação precisa ser vista de forma transcendente. Ou seja, para além da circulação de informações. Considerando as dimensões dialógicas estrategicamente geridas e espontânea, busca-se um olhar incluir o diálogo como metodologia no contexto da perspectiva estratégica da comunicação. A partir dessa compreensão, será possível aprimorar o sistema de prevenção e gestão de risco, de forma a estabelecer um lugar de encontro e significado compartilhado que proteja as pessoas e as organizações dos impactos negativos das crises.

\section{REFERÊNCIAS}

ALMEIDA, António Betâmio. Risco e gestão do risco. Questões filosóficas subjacentes ao modelo técnico conceptual. Territorium, n. 18, p. 23-31, 2011.

BECK, Ulrich. "Momento cosmopolita" da sociedade de risco. ComCiência, n. 104, p. 0-0, 2008.

CARBONARA, Vanderlei. Educação, ética e diálogo desde Levinas e Gadamer. 2013. Disponível em: http://meriva.pucrs.br:8080/dspace/handle/10923/2900. Acessado em: 10/5/2019.

CASTELLS, Manuel. Comunicación y Poder. Madrid, AlianzaEditorial, 2009.

CASTELLS, Manuel. Redes de indignação e esperança. Tradução Carlos Alberto Medeiros. Rio de Janeiro: J. Zahar, 2013.

COTTA, Francis Albert. Protocolo de intervenção policial especializada: uma experiência bem-sucedida da polícia militar de Minas Gerais na gestão de eventos de defesa social de alto risco. Revista Brasileira de segurança Pública. São Paulo. Ano, v. 3, n. 5, 2009.

FORNI, João José. Gestão de Crises e Comunicação: o que gestores e profissionais de comunicação precisam saber para enfrentar crises corporativas. São Paulo: Atlas, 2013.

FRANÇA, Vera. O objeto da comunicação/A comunicação como objeto. Teorias da comunicação, v. 2, p. 39-60, 2001.

GIDDENS, Anthony. Mundo em descontrole. Editora Record, 2007.

HJARVARD, Stig. Da mediação à midiatização: a institucionalização das novas mídias. Parágrafo, v. 3, n. 2, p. 51-62, 2015.

HJARVARD, Stig. A midiatização da cultura e da sociedade. Editora Unisinos, 2014. LIMA, Fábia Pereira; BASTOS, Fernanda de Oliveira Silva. Reflexões sobre o objeto da comunicação no contexto organizacional. Propostas conceituais para a comunicação no contexto organizacional. São Caetano do Sul: Difusão, p. 25-48, 2012. 
MARTINO, Luiz C. De qual comunicação estamos falando. Teorias da comunicação: conceitos, escolas e tendências. Petrópolis: Vozes, p. 11-26, 2001.

MASSONI, Sandra. Comunicación y desarrollo. Encuentros en la diversidad. In: THORNTON, Ricardo D.; CIMADEVILLA, Gustavo. Grises de la Extensión, la Comunicación y el Desarrollo. Ediciones INTA. Buenos Aires, 2008.

MATTELART, A. e MATTELART, M. - História das Teorias da Comunicação. Porto: Campo das Letras, 1997.

MORIN, Edgar. Ensinar a viver: manifesto para mudar a educação. Porto Alegre: Sulina, 2015 .

OLIVEIRA, Rosângela Florczak de. Dimensões possíveis para o diálogo na comunicação estratégica: Tecituras e religações entre o relatório de sustentabilidade e as mídias sociais da Vale. Tese (Doutorado em Comunicação). Porto Alegre: PUCRS.2016.

PÉREZ, Rafael Alberto. Comunicación estratégica: sí claro. Pero,‘ qué implica "estratégica"? Revista Académica de Comunicación y Ciencias Sociales, n. 2, 2012.

PINTO, Julio. Comunicação organizacional ou comunicação no contexto das organizações. Interfaces e tendências da comunicação no contexto das organizações. São Caetano do Sul: Difusão, 2008.

SANTAELLA, Lucia. Desafios da ubiquidade para a educação. Revista Ensino Superior Unicamp, v. 9, p. 19-28, 2013.

SHINYASHIKI, Roberto Tadeu; FISCHER, Rosa Maria; SHINYASHIKI, Gilberto. A importância de um sistema integrado de ações na gestão de crises. Organicom, v. 4, n. 6, p. 148-159, 2007.

SHINYASHIKI, R. T. A influência da auto-eficácia dos gestores na administração de crises. Tese (Doutorado em Administração) - Departamento de Administração da Faculdade de Economia, Administração e Contabilidade. São Paulo: Universidade de São Paulo, 2006.

SILVA, Anielson Barbosa da; RABELO, Luiza M. Bessa. A emergência do pensamento complexo nas organizações. Revista de Administração Pública, v. 37, n. 4, p. 777-796, 2003.

STEELMAN, Toddi A.; MCCAFFREY, Sarah. Best practices in risk and crisis communication: Implications for natural hazards management. Natural hazards, v. 65, n. 1, p. 683-705, 2013.

WHEATLEY, M. J. Liderança e nova ciência: descobrindo ordem em um mundo caótico. Tradução Adail Ubirajara Sobral, Maria Stela Gonçalves. São Paulo: Cultrix, 2006.

WOLTON, D. É preciso salvar a comunicação. São Paulo: Paulus, 2006.

WOLTON, D. Informar não é comunicar. Porto Alegre: Sulina, 2010. 


\section{Rosângela Florczak Oliveira}

Doutora e Mestre em Comunicação pela Pontifícia Universidade Católica do Rio Grande do Sul (PUCRS), com especialização em Sociologia pela Universidade Federal do Rio Grande do Sul (UFRGS) e graduação em Comunicação Social - Jornalismo pela Universidade Federal de Santa Maria (UFSM). Professora de cursos de Graduação e da Pós-graduação na ESPM. Diretora do Capítulo RS da ABERJE. Sócia-diretora da Verity Consultoria.

E-mail: roflorczak@gmail.com 